\title{
RICARDO CARVALHO CALERO E 0 TEATRO
}

\author{
RICARDO CARVALHO CALERO AND THE THEATRE
}

\section{Laura Tato Fontaíña Universidade da Coruña}

\begin{abstract}
Resumo: Neste artigo, a autora fai un percurso polas actividades dramáticas de Ricardo Carvalho Calero. Comeza coa súa primeira obra, escrita en 1934, dentro do programa de modernización e actualización do teatro galego iniciado polas Irmandades da Fala e continuado polo Grupo Nós, a xeración das Vangardas e a do Seminario de Estudos Galegos. Pasa polas obras escritas na soidade da posguerra e os traballos relacionados co teatro escolar en Fingoi, para acabar coas últimas reflexións do autor sobre os pactos da Transición política, en 1980, coa escrita de Os xefes.
\end{abstract}

Abstract: This article examines the dramatic activities of Ricardo Carvalho Calero. Its analysis begins by focusing on his first play, written in 1934, within the program of modernization and updating of the Galician theatre, initiated by the Irmandades da Fala, continued by the Nós Group, the subsequent Avant-Garde Generation and the Seminary of Galician Studies. It assesses the works written in the cultural solitude that followed the Spanish Civil War and the works related to school theatre in Fingoi, and concludes by analysing the author's final reflections on the agreements reached during the political transition following the end of the Franco regime, with the writing of Os xefes [The Bosses] in 1980.

Palabras chave: Ricardo Carvalho Calero, teatro galego, historia do teatro, crítica literaria.

Key words: Ricardo Carvalho Calero, Galician theatre, history of theatre, literary criticism. 
Cando estudamos calquera das facetas como escritor de Ricardo Carvalho Calero non podemos ignorar nin o seu labor como crítico nin o seu inxente traballo como historiador da literatura, pois a través dos textos que nos deixou nestes campos poderemos entender moitos dos matices da súa obra de creación. Deste modo, canto ao xénero dramático, Carvalho, como case todos os grandes escritores das xeracións de preguerra, entendía que a construción dun teatro nacional era un labor común ao que había que contribuír, aínda que fose para o futuro. Así o declaraba el mesmo:

O escritor galego daquela época, formado como eu me formei, de nengunha maneira dava por definitiva a situazón que entón reinava, de xeito que tamén hai que considerar que alentava en nós a esperanza doutro tempo futuro en que a literatura galega recuperase a plenitude que xa iniciara con anterioridade à guerra, e que superase incluso aquela situazón, de modo que havia que imaxinar un tempo futuro en que existise un teatro galego pleno con obras representadas (Fernán-Vello e Pillado 1986, pp. 109-110).

Por esta razón, a súa produción dramática presenta as mesmas características, á respecto da secuencia escrita/publicación/estrea, que todas as pezas dos seus compañeiros de xeración, e esa secuencia normalmente está truncada por lapsos de tempo tan grandes que resulta conveniente coñecelos para entendermos a evolución do teatro en toda a súa dimensión. Porén, como historiador da literatura era consciente da importancia que tiñan eses datos e el mesmo facilitou as datas de escrita, de publicación e, na medida en que foi coñecedor, de estrea e representacións das súas pezas dramáticas.

En 1934, o Partido Galeguista na III Asemblea, celebrada en Ourense, ademais de tratar cuestións políticas de grande entidade, encomendou ás Mocidades Galeguistas un relatorio sobre o teatro co fin de abordar, definitivamente, a renovación escénica da que se viña falando e discutindo desde había un ano, cando o presidente das Mocidades, Francisco Fernández del Riego (1933), en carta aberta á agrupación de Vilanova de Lourenzá, lembrara que só se debía representar teatro galego. Pola correspondencia entre Castelao e Otero Pedrayo (Tato Fontaíña 2011), así como polas notas que ían saíndo na prensa, nomeadamente en El Pueblo Gallego, sabemos que unha das facetas desa renovación estaba en marcha en Pontevedra, no cadro de declamación das Mocidades e baixo a supervisión de Castelao, que preparaba o que se coñecía na contorna nacionalista como Teatro de Caretas, Teatro de Máscaras (Carballeira 1934) ou, simplemente, como Teatro de Arte. 
Carvalho Calero preparou a súa contribución a esta tarefa común escribindo a peza $O$ fillo. Acción dramática en dous actos, o segundo dividido en dous cadros, que estaba entregada na editorial Nós para a súa publicación cando estalou a sublevación fascista, e que, por tanto, foi destruída, como todos os fondos da imprenta de Ánxel Casal. Cando saíu do cárcere franquista, instalado no seu Ferrol natal, e doce anos despois de escrita a peza, en 1947, enviouna ao certame do Centro Gallego de Buenos Aires e gañou o premio de teatro que levaba o nome de Castelao.

A peza responde aos principios xerais do teatro de preguerra, no sentido de que desvincula a lingua dos ambientes populares (o escenario en que se desenvolve a acción é un pazo e a protagonista, unha fidalga), mais incorpora elementos da cultura popular (as panxoliñas de Nadal e o desafío amoroso) de forma que integra a modernidade coa tradición, o culto co popular. A fábula xira en torno á personalidade da fidalga Joana, que devece por ter un fillo mais rexeita ter contacto carnal con varón, de forma que cando alguén abandona un neno na súa porta, interpreta o feito como un milagre: igual que a Virxe María, ela vai ser nai e seguir sendo virxe. No segundo acto, a fidalga goza da maternidade até que é coñecedora de que o seu neno ten unha orixe bastarda, de que "é fillo do pecado", polo que renuncia a el entregándoo a Estrela, criadiña moza que, como a señora, soña con ser nai mais cun pai para os seus fillos. O conflito resólvese coa loita interior da fidalga que a conduce a reconsiderar a súa decisión e que, no plano estético e dramático, o autor plasma dun xeito realista creando a figura da Descoñecida (Joana de moza) que suplanta á fidalga.

Na mesma liña d'O fillo, Carvalho comeza a escribir en 1936 Isabel. Comedia en tres actos. Aínda que non a puido rematar até 1945, a peza nacía coa urxencia de haber un grupo preparado para a levar a escena, polo que o autor aproveitou elementos da obra anterior; en concreto, o ambiente de pazo rural e as personaxes da criada vella e mais da criada nova que informan ao espectador dos antecedentes do conflito que se vai desenvolver (Carballo 1985). Mario vive na montaña profundamente afectado pola morte da súa muller, Isabel, quen, misteriosamente, aparece viva no final do primeiro acto; no segundo, reciben a visita dun vello amigo, Quiroga, que parece coñecer o misterio que envolve a "resurrección" da dona do pazo. Finalmente, no terceiro acto, desvélase o misterio: a segunda Isabel fora contratada polos amigos de Mario para o tirar da súa melancolía. Porén, o que non deixaba de ser unha broma de dubidoso gusto foi aceptado polos protagonistas como realidade, caendo o pano sobre un Mario e unha Isabel que asumiron plenamente a ficción e deciden seguir vivindo de costas á realidade.

Nun primeiro momento, Carvalho Calero non considerou que estas dúas pezas fosen dignas de pasar á posteridade e non as incluíu no volume de teatro que publicou en 1971 (4 Pezas), mais como historiador da literatura era consciente de 
que para entendermos tanto a evolución do teatro galego como a súa historia, era preciso coñecermos todo, polo que viron a luz en 1982, no volume Teatro completo, onde deixou constancia dos anos en que foran redixidas. A súa lucidez de crítico non lle permitía ignorar as deficiencias destas pezas de principiante e, tal vez por iso, dedicou ao seu comentario e xustificación bastante tempo e espazo. Esas demoradas explicacións serven para comprendermos o concepto tan clásico, tan conservador, que tiña Carvalho do teatro, pois incide en conceptos como as unidades de lugar e acción e mesmo considera que O fillo é máis moderna, máis vangardista, do que Isabel porque contén escenas simbólicas (o Anxo, a Descoñecida):

Ainda que a psicología na segunda peza oferece máis refinamento que na primeira, non hai en Isabel escenas expresionistas ou simbólicas. Por duas veces, en $O$ fillo o espectador ve o indivisíbel, ve o interior de Joana. Nada semellante hai en Isabel, na que unha técnica completamente realista nos fornece a visión do que realmente verían os ollos dos presentes nos acontecimentos. Neste sentido, a peza máis moderna é menos moderna -menos vanguardista, menos experimental - que a anterior (Carballo 1985, p. 7).

Para nós a valoración é outra, pois se ben $O$ fillo estaba máis cerca das vangardas por mor das escenas simbolistas da entrega do neno por un Anxo e da aparición da Descoñecida, Isabel resulta máis actual polo xogo do teatro dentro do teatro, a suplantación da personalidade e as relacións entre ficción e realidade. De todos os xeitos, ambas as dúas forman parte do teatro de preguerra e, de entre as tendencias que nas décadas de 1920-1930 se propuxeran para renovar a escena galega, Carvalho optou polo simbolismo, como Vicente Risco, mais cunha forte pegada do realismo de Jacinto Benavente.

Unha vez liberado do cárcere franquista, no exilio interior do seu Ferrol natal, Carvalho volveu ao teatro e, en 1948, redixiu tres pezas: A farsa das zocas; A sombra de Orfeo. Comédia en tres lances e mais A árbore. Auto en tres escenas e un epílogo-prólogo. As dúas primeiras continúan ou enlazan co teatro anterior á guerra, a terceira responde á corrente existencialista imperante na poesía galega da altura.

A farsa das zocas, peza en dous actos, encaixaría perfectamente no Teatro de Caretas con que Castelao proxectaba renovar a escena durante a II República e para o que Otero Pedrayo redixiu os textos que conforman o volume Teatro de Máscaras, pois coincide con eles na mestura de elementos populares con elementos cultos, no expresionismo e na estilización da materia dramática. Parte dun relato popular e aplícalle unha técnica que Fernández Roca cualificou de naif e que consiste en utilizar os recursos do teatro primitivo: autopresentación dunhas personaxes moi estilizadas e dunha peza, acción lineal na cronoloxía dos feitos, 
interpelacións ao público... creando a impresión dun "retábulo de aldea ou dun cartaz de cego" (Fernández Roca 2000, p. 26) de carácter lúdico, aínda que o seu autor afirmou que podía admitir tamén unha lectura social que se nos escapa. $\mathrm{O}$ primitivismo inxenuo da farsa é un efecto intencionado do autor, que botou man dos recursos do teatro chinés. Fernández Roca resumiu así o esquema da peza:

Acto I: 1) Carraxe de Edelmira contra Breixo, o seu home, e Divina, a súa cuñada; 2) roubo do mel por estes dous; 3) morte de Edelmira sen testamento; 4) falso testamento argallado pola cuñada. Acto II: 1) Boa vida dos herdeiros e dos seus cómplices; 2) aparición de Edelmira ao Xocas; 3) visita deste ao Notario para contar a verdade; 4) castigo aos culpábeis por medio das zocas. (2000, p. 25).

Esta peza, despois de que "se suprimiu todo aquilo que poderia estimar-se un pouco incompatível co sentido que se lle queria dar oficialmente à educazón dos nenos" (Fernán-Vello e Pillado 1986, pp. 122-123) foi estreada polo propio autor co seu alumnado no Colexio Fingoi, e acabou sendo a máis celebrada e representada da súa produción dramática. Publicouna na revista Grial en 1963. O mesmo carácter lúdico ten $\mathrm{O}$ redondel, adaptación do drama $\mathrm{O}$ círculo de giz, de Li HsingTao, realizado en 1951, para que fose representado polo mesmo alumnado de Fingoi. Neste centro de ensino, cun elenco de rapaces e rapazas e para o público que adoita asistir ás representacións escolares, desenvolveu Carvalho Calero o seu labor de director de escena.

A comedia en tres lances A sombra de Orfeu, datada tamén en 1948, foi cualificada polo seu autor de comedia psicolóxica e posta en relación con Isabel. A acción desenvólvese nunha casa rústica habilitada para estudo de artista onde un compositor se vai enfrontar con tres mulleres, tamén artistas, mentres outras tres observan, a modo de coro clásico, desde un segundo plano. Rafael Golpe, admirado e atractivo, déixase retratar pola súa exmuller, Mariana, e mais por unha discípula desta, Magdalena; a rivalidade das dúas pintoras ultrapasa as fronteiras do artístico, pois a que o amou plasma o seu rancor e a que o ama plasma a súa devoción; e mentres elas litigan, el déixase amar e coidar por Luísa, especie de criada-secretaria que renunciou á súa propia carreira artística para servir o mestre. Tres tipos femininos: Mariana, a muller independente que non consente en ficar subordinada á carreira do seu home; Magdalena, a fermosa deusa fatal que aposta arriscadamente pola sedución; e mais Luísa, a escrava submisa que renuncia a todo, mesmo ao amor físico, por se manter á carón do amado. Das tres posibilidades, Rafael opta por Luísa. En palabras do autor: 
Orfeo refuga ser devorado polas feras que o ameazan coas fauces da sua feminidade enervante, e o Mestre conserva so ao seu carón a feminidade da sua fiel e digna colaboradora, feminidade sublimada en dedicación profisional, e que so a costa desa sublimación mantén a privilegiada posición de sombra familiar do Mestre, a quen non inquieta e que, naturalmente, a estima como preciosísimo coadjuvante da sua obra (Carballo 1985, p. 8).

Baseándose nunhas declaracións do propio Carvalho sobre a imbricación de vida e obra nos escritores e, por tanto, sobre a necesidade para o historiador da literatura de ter sempre presente a biografía dos autores, João Guisan incidía no carácter autobiográfico desta peza sinalando a relación que a personaxe central, Rafael Golpe, presenta con outras posíbeis actividades artísticas que Carvalho imaxinaba para si mesmo:

Porque esta cita tende já uma primeira ponte entre a vida e a obra e fai com que vejamos no personagem central (ou talvez no espectador central) de A sombra de Orfeu, Rafael Golpe, compositor musical, a sombra realmente, nom de Orfeu, mas de Carvalho Calero, ou de um "super Ego" de Carvalho Calero, estilizado e idealizado, mas um pouco com a atitude intelectual distante, temperada, respeitosa e um pouco fria que ele tinha. [...] A obra constitui assim uma espécie de diálogo, ou solilóquio com ele mesmo, em que se coloca precisamente muitas questões acerca do tema desta intervençom: a arte e a vida (Guisan 2002, p. 211).

A terceira peza do ano 1948 foi A Árbore. Auto en tres escenas con epílogo-prólogo. Segundo informa o propio Carvalho Calero no prefacio ás 4 Pezas, de 1971, escribiuna para ser representada inmediatamente, mais non chegou a estrearse daquela e foi publicada na revista Grial en 1965. Ao longo de tres escenas idénticas -datadas en 1908, 1928 e 1948-, o Home, que vai madurando e avellando co paso do tempo, dialoga coa Muller, eternamente conxelada nos dezaoito anos, que responde ás palabras de amor con tópicos, mostrando a superficialidade máis banal e unha grande asimilación do código moral e social estabelecido. $\mathrm{O}$ "epílogo-prólogo", datado "fóra do almanaque", explica estas situacións escenificando o momento en que Eva consegue, con engano, que Adán coma do froito prohibido. Fronte aos soños do Home, os valores materiais da Muller; fronte ao coñecemento de El, a submisión de Ela ao socialmente correcto. $\mathrm{O}$ autor explicaba o fracaso da relación no seguintes termos: 
O home e a muller están defrontados, a carón da Arbre. Debían ser felices, só un home e unha muller, nunha eterna primavera. Pero hai monicións, mamáis, curmáns, soles, neves cañas... Hai circunstancias. E, craro, o amor é tamén, orteganamente, o amor e as súas circunstancias (Carballo 1971, p. 16) .

Esta visión absolutamente pesimista das relacións amorosas e da súa imposibilidade de realización responden a unha etapa vital de Carvalho Calero caracterizada pola soidade, o exilio interior, a penuria económica e en que estaba, ademais, sometido a un control policial constante. Son os anos en que a súa obra poética, recollida en Anjo de terra (1950), expresa unha fonda reflexión sobre a condición do home, "anjo de terra", expulsado da cidade dos verdadeiros anxos (o "azul"), que non acepta a súa condición de desterrado porque non é capaz de gozar plenamente do mundo no que foi recluído (o "verde"). A mesma radical diferenza entre Home e Muller que aparecía en A Árbore está recollida en dous poemas de Anjo de terra: El non pode gozar da vida por mor da súa arela de transcendencia, mentres Ela acepta plenamente o mundo e intégrase nel. De feito, nas palabras que redacta para presentar a peza dramática, afirma que é unha reflexión sobre o matrimonio:

ao ver aos actores interpretar $A$ arbre, coida que o que quixo facer hai vinte anos -vintedóus- foi unha "moralidade" ao xeito antigo. Un auto cáxeque sacramental, anque non eucarístico. Máis ben matrimonial. Porque nun certo contesto o asunto é o matrimonio (Carballo 1971, p. 15).

Entre a escrita d'A Árbore e a da seguinte peza van transcorrer vinte anos. Vinte anos investidos no labor docente e investigador, para alén da publicación dun poemario, Saltério de Fingoy (1961), que a crítica coincide en sinalar como un punto de inflexión na traxectoria poética de Carvalho, como un libro de madurez, como peza fundamental na súa produción, en que se privilexia a voz reflexiva do poeta na súa procura de transcendencia e na desolación da descuberta de que Deus - o Absoluto - non existe (Pallarés 1992). Tampouco faltan neste poemario aquelas composicións centradas na muller, á que admira como obxecto estético, mais tamén a observa como animal social e, sobre todo, como espello das convencións morais e sociais do réxime político que lle tocaba vivir e padecer. $\mathrm{O}$ control, mesmo dentro das familias, que a Ditadura franquista exerceu a través das mulleres -educación, confesionarios e Sección Feminina - non podía escapar aos ollos deste intelixentísimo profesor que defendera os principios nacionalistas e republicanos e viviu sempre rodeado de mulleres. De aí que, nesta etapa da súa 
vida, se lle presente a relación home/muller, e o amor, como un imposíbel e que a responsábel dese fracaso sexa sempre Ela.

Estas liñas temáticas, tinxidas pola mesma desesperanza existencialista, inspiran en 1969, o Auto do prisioneiro, obra que, tanto polo título como pola súa adscrición xenérica, enlaza co'A Árbore. Aínda que a respecto desta peza se ten falado de Kafka, Sartre e Beckett, o propio Carvalho Calero declarou que, igual que A Árbore responde ás liñas do auto sacramental español e, sobre todo, da "moralidade" medieval que, como é sabido, consistía nunha alegoría dramática en que o protagonista achaba personificacións de atributos morais que intentaban conducilo polo camiño correcto, seguindo os principios cristiáns da época:

Con relación a ela ten-se falado de Beckett e de Kafka. Na época en que se estreou, cando se consideraba imoral en certos meios toda literatura independente, uns interpretaron-na benevolamente como dirigida contra a sociedade de consumo, e outros, detectando nela unha preocupación espiritualista, estimaron-na talvez expresión dunha postura ideológica incompatíbel co materialismo dialéctico. Eu creio que tencionei plasmar nunha forma moderna, poética e incisiva, a angústia do home engaiolado na sua finitude, mais cunha faústica sede de alén (Carballo 1985, pp. 9-10).

Así, o dramaturgo redixe unha moralidade antiga actualizada no ambiente e encarnando as personaxes alegóricas en seres individuais: un Prisioneiro semellante ao calderoniano Segismundo que quere comprobar empiricamente a existencia dese Director que din é o seu pai. Os argumentos que, ao longo da obra, se utilizan para o facer desistir do seu empeño variarán segundo a personaxe a quen interroga o Prisioneiro: para o Guardián, a figura máis baixa na escala social, é unha procura absurda porque a felicidade radica en que alguén decida por ti; o Oficial utiliza a argumentación de que se o sistema funciona é porque existe un Director que dá as ordes e atribúe a 'doenza' do Prisioneiro ao funesto costume de pensar; a Nai intenta que acepte a súa situación apelando á resignación cristiá; os Amigos e as Amigas envexan a súa forma de vida polas comodidades materiais que posúe; e Laura, que cobre as necesidades eróticas do Prisioneiro e aspira a substituír o Director nas súas ansias, visto que as armas de sedución tradicionais non abondan, desprega unha nova: o seudointelectualismo conseguido nas aulas universitarias.

A obra desenvólvese no día en que o Prisioneiro cumpre trinta simbólicos anos e ábrese coa visita, mentres el dorme, dunha Nena que lle anuncia que esa será a derradeira xornada da súa vida. No fondo da cela permanecerá sempre fechada a porta que comunica coa Dirección e durante toda a obra o Prisioneiro 
intentará, directa ou telefonicamente, pórse en contacto con ela. A través, sobre todo, das figuras femininas o autor realiza unha demoledora crítica da sociedade de consumo e, outra volta, do mundo feminino, polo que facilita unha interpretación sociolóxica da peza. De todos os xeitos, a derradeira visita que recibe o Prisioneiro volve a ser a da Nena para lle ofrecer un xarope que acougue o seu espírito; é a Morte e, no último alento, soa o teléfono e comeza a se abrir a porta; mais no seu interior, que o Prisioneiro xa non pode ver, non hai nada, só baleiro. Este final permite que cada quen realice a súa interpretación: a porta abriu, por tanto, o ser humano coñece a Deus despois da morte; ou ben, detrás da porta non hai ninguén, por tanto, Deus non existe. De novo a ambigüidade carvalhana, do mesmo xeito que a Morte pode ser aceptada negativa ou positivamente, segundo a vexamos como o terríbel mal que remata a vida ou como o sono que nos proporciona a paz definitiva, a fin da mágoa, da coita e da angustia. $\mathrm{O}$ Auto do prisioneiro foi publicada, xunto con A Árbore, A sombra de Orfeu e mais A farsa das zocas, en 1971, no volume 4 Pezas e estreada en 1974 no Instituto de Ensino Medio de Vilalba (Lugo).

Había de transcorrer máis dunha década até que Carvalho volvese ao teatro e escribise, en 1980, a mellor das súas obras: Os xefes. Igual que co Auto do prisioneiro, o autor declarou que a incubara durante moito tempo. El definiuna como "comedia política", aínda que quizais fose máis acertado cualificala de drama. $\mathrm{O}$ primeiro acto desenvólvese no cuartel xeral do exército branco que está sitiando Gaibor, capital de Gurlandia. Os xenerais que compoñen a Plana Maior do exército do Xeneral Brañas comentan a localización xeográfica da cidade e o estado da guerra, Brañas dá instrucións sobre a estratexia de ataque e cérrase o acto cunha rolda de prensa do Ministro de Información.

O segundo acto, á mesma hora do solpor que o anterior, transcorre no campo contrario, no dos sitiados, o do exército negro comandado polo Xeneral Dragón, e as situacións son as mesmas: comentario por parte dos xenerais da situación bélica, confidencias de Dragón ao seu home de confianza e entrevista da Ministra de Información coa única periodista á que lle foi permitido cruzar o sitio en representación de todos os seus colegas estranxeiros. Tanto polo discurso dos militares como dos políticos é doado identificarmos o exército branco coas forzas sublevadas en 1936 e o exército negro, coas forzas republicanas: os primeiros autoproclámanse defensores da tradición cristiá, do culto á patria, do honor militar e das virtudes familiares, acusando aos segundos de seren ateos, anarquistas e destrutores da familia e da propiedade privada. Mesmo os brancos utilizan frases dos xenerais fascistas Mola e Franco, e en boca da ministra dos negros están os lemas anarquistas de 1936 e o lendario "Non pasarán”. A derradeira pregunta que 
os xornalistas fan aos ministros é se existe a posibilidade dunha paz negociada e ambos os dous responden contundentemente que non.

O terceiro acto desenvólvese de mañá, nunha embaixada estranxeira. A través dun diplomático e da súa secretaria sabemos que se asinou un armisticio e que, clandestinamente, Dragón e Brañas celebrarán unha entrevista. Os xenerais, despois de se ofrecer mutuamente unha rendición honrosa, que ningún acepta, chegan a un acordo: sexa cal for o resultado da guerra, o vencedor suprimirá os elementos radicais do seu bando - ben a extrema dereita, ben a extrema esquerdae gobernará cunha política de centro. Entenden ambos que esa guerra civil non é máis que a primeira parte dunha outra guerra que rematará no futuro. A respecto da interpretación deste acordo, Carvalho Calero (1985, p.11) afirmou: "Pode-se pensar: dous homes de honor con verdadeiro sentido patriótico. Ou tamén: dous xefes que pactan un engano ás masas que os apoian. Unha apologia da democrácia ou unha sátira da oligarquia".

Tamén se ocupou Carvalho de indicar que, se ben os primeiros actos estaban localizados na Guerra Civil, o verdadeiro cerne da obra radicaba nese acordo político en que os Xefes resultaban ser ideoloxicamente idénticos, e onde ficaba recollido que ningún deles estaba disposto a permitir a existencia da banda extrema da súa ideoloxía polo que, en realidade, planificaban un golpe de estado. Tendo en conta o que aconteceu na denominada Transición, a lectura da obra debe realizarse en clave coetánea á súa escrita, non en clave histórica. En 1986, Carvalho Calero mantiña esta opinión sobre a política do momento:

En muitos aspectos, a política oficial parece inspirada pola crenza de que é xurídica e moralmente aceitável unha filosofia segundo a cal a disidéncia, a oposizón, pode e deve ser eliminada, o cal, naturalmente, é absolutamente erróneo dentro dun sistema que pretendamos democrático e liberal (Fernán-Vello e Pillado 1986, p. 234).

A peza responde ao concepto, absolutamente clásico, que tiña Carvalho sobre como debía ser construída unha peza de teatro ben feita; concepto en que eran fundamentais a orde, o equilibrio e a proporción. Así, tipograficamente, marca a división dos actos en escenas (oito nos actos I e II, e once no III) e, estruturalmente, realiza unha homenaxe a Castelao, a Os vellos non deben de namorarse. Dos tres actos que compoñen a obra, o terceiro foi o primeiro que escribiu (Carballo 1985, p. 10), igual que aconteceu con Pimpinela, terceiro lance da obra de Castelao. Dragón e Brañas son encarnacións dun mesmo "personema" (Carballo 1989, pp. 233-299), son actantes do Xefe; como o grupo de xenerais, tanto brancos como negros, son encarnacións do Militar; e o Ministro e a Ministra, do Político. 
Os xornalistas desempeñan aquí o papel que, en Os vellos non deben de namorarse, desempeñaba o Coro de Mulleres, é dicir, a voz do pobo que, nesta ocasión, en lugar de opinar, expón as súas dúbidas sobre o resultado e as consecuencias da guerra. A pesar disto, tamén como na obra de Castelao, esas personaxes presentan trazos que as individualizan e para iso, os xenerais negros falan de "soberanía nacional" e "democracia", e os xenerais brancos de "honor" e "patria". Tamén os diferenza o feito de que o mundo do campamento branco sexa exclusivamente masculino, mentres no negro as mulleres teñen un papel semellante ao dos homes. É máis, mesmo se aplicamos a Os xefes a análise estrutural que Carvalho aplicou a Os vellos non deben de namorarse, achamos novas equivalencias. As situacións da obra do ferrolán son:

1. Comentario dos xenerais sobre a situación da guerra.

2. Confidencias do Xefe ao seu segundo.

3. Rolda de prensa.

Igual que a orde das situacións variaba nos diferentes "lances" da obra de Castelao, tamén o fan na de Carvalho: no I acto a orde das secuencias, ou situacións, é a que acabamos de enumerar $(1,2,3)$, mentres que no II acto, a orde varía (1, 3, 2). Como é ben coñecido, a escrita d'Os xefes non era a primeira homenaxe literaria de Carvalho Calero a Castelao pois, o ano anterior, en 1979, xa tratara o tema do amor do Vello pola Moza no precioso texto Aos amores serodios. Texto que é unha arriscada mestura de ensaio, relato e poesía.

Agás na faceta de historiador da literatura, o mellor da obra carvalhana foi producido na década de 1980: os poemarios Cantigas de amigo e outros poemas (1986) e o póstumo Reticências... (1986-1989), o romance Scórpio (1987) e todos os ensaios e artigos en que ficou recollido o seu posicionamento respecto da cuestión lingüística e normativa. Mais nesa década prodixiosa non volveu sobre o teatro, de forma que Os Xefes ficou como a súa derradeira peza dramática.

\section{REFERENCIAS BIBLIOGRÁFICAS:}

Carballeira, Juan (1934). Para el logro de un teatro nuestro. El Pueblo Gallego, 15/ XI/1934, 1.

Carballo Calero, Ricardo (1971). 4 Pezas. Vigo: Galaxia.

Carballo Calero, Ricardo (1985). Sobre o seu teatro. Cadernos da Escola Dramática Galega, 56, 3-11.

Carballo Calero, Ricardo (1989). Escritos sobre Castelao. Barcelona: Sotelo Blanco. 
Fernandez del Riego, Francisco (1933). Villanueva de Lorenzana. Carta abierta a la "Mocedade Galega". El Pueblo Gallego, 8/I/1933, 8.

Fernández Roca, Xosé A. (2000). Carballo Calero no seu teatro. En: Homenaxe a Carvalho Calero. Ferrol: Cadernos de Medúlio, 23-28.

Fernán-Vello, Miguel A. e Pillado Mayor, Francisco (1986). Conversas en Compostela con Carballo Calero. Barcelona: Sotelo Blanco.

Guisan Seixas, João (2002). Carvalho Calero: o teatro e a vida. En: Teresa López e Francisco Salinas eds., Actas do Simposio Ricardo Carvalho Calero. "Memoria do século”. A Coruña: Universidade da Coruña / AS-PG, 205-225. Dispoñíbel en: https://doi.org/10.17979/spudc.9788497497671.205

Pallarés, Pilar (1992). Fillo de Eva (88 poemas de Ricardo Carvalho Calero). Ferrol: Sociedad de Cultura Valle-Inclán.

Tato Fontaíña, Laura (2011). O teatro de Ricardo Carvalho Calero. En: Carlos C. Biscainho Fernandes e Xosé M. Sánchez Rei, coords. Ricardo Carvalho Calero: ciencia, literatura, nación. A Coruña: Universidade da Coruña, 201-2013. 